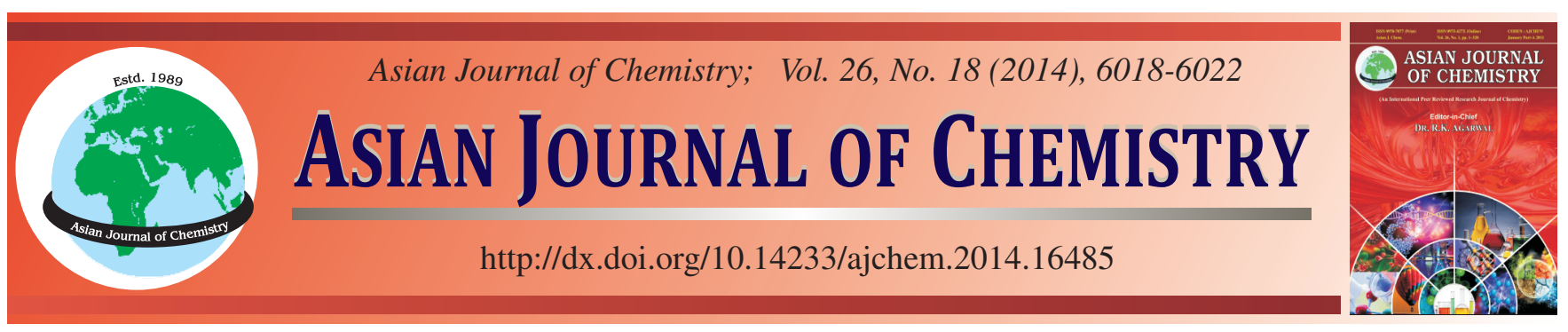

\title{
Toughening of Epoxy Resin via Silane Terminated Urethane Including Pre-Hydrolyzed Tetraethoxysilane
}

\author{
ILYAS KARTAL
}

Faculty of Technology, Marmara University, Istanbul, Turkey

Corresponding author: Tel: +90 2163365770 , E-mail: ilyaskartal@ marmara.edu.tr

\begin{abstract}
In this study, firstly, silane terminated urethane was synthesized from poly(hexamethylene carbonate) diol and 3-isocyanatopropyltrimethoxysilane. Prepared solutions of inorganic part (silane terminated urethane + pre-hydrolyzed tetraethoxysilane) were mixed with epoxy-hardener mixture to obtain hybrid solutions. Various hybrid solutions were prepared using different epoxy/inorganic part solution compositions. Furthermore, the effect of silane terminated urethane on the mechanical and morphological properties of epoxy was investigated. The structure and properties of the composites are characterized using a scanning electron microscopy. Epoxy/silane terminated urethane hybrid materials were subjected to examinations to obtain their tensile strength, three point bending properties, hardness, izod impact strength. Incorporation of silane terminated urethane into the epoxy resin greatly modified the impact behavior of hybrids.
\end{abstract}

Keywords: Polyurethane, Epoxy resin, Hybrid polymer.

\section{INTRODUCTION}

Epoxies are a class of polymers known as thermosettings. In cured state, these polymers have an amorphous and highlycrosslinked structure ${ }^{1-2}$. This microstructure results in many useful properties for structural engineering applications, such as a high modulus and failure strength, low shrinkage, ease of cure, high thermal resistance, chemical resistance, good adhesion to many substrates, low creep and good performance at high temperatures ${ }^{3-4}$. Epoxy polymers are used in a wide range of applications such as adhesives, sealants, coatings, paints and matrices of polymer based composites. Their usage encompasses many industry sectors ranging from microelectronics to aerospace to transportation to construction engineering ${ }^{5-6}$.

Unmodified epoxy resins are generally brittle and exhibit low elongation after cure. These polymers usually craze on their free surfaces and the crazed areas are converted into cracks, which propagate with brittle energy absorption resulting in fracture. The high glass transition temperatures of epoxy polymers are the result of cross-linked structures. In epoxies, high glass transition temperatures lead to reduced toughness and damage tolerance ${ }^{7}$.

Several attempts have been made to improve fracture resistance of epoxies ${ }^{8}$. These are as follows: (a) having a more flexible backbone through chemical modification, (b) increasing the molecular weight, (c) lowering the cross-link density, (d) incorporation of a dispersed soft phase which toughens the cured epoxy (e) addition of inorganic fillers/reinforcements into the pure epoxy resin 9 .

The last two methods are commonly applied toughening methods for epoxies. However, some toughening materials often reduce other properties such as elastic modulus, strength and glass transition temperature etc. Such tougheners are, for example, liquid rubbers, spherical rubber particles ${ }^{10}$, core shell particles ${ }^{11}$, microvoids ${ }^{12}$, hyperbranched polymers ${ }^{13}$ and combinations of these $\mathrm{e}^{14}$. Modifiers less rigid than the polymer matrix may serve as excellent tougheners in matrices which show ductility to some degree. Rubber particles, for example, can induce the formation of microvoids which is subsequently accompanied by the activation of yielding processes due to the reduction of the local yield stress, i.e., the plastic resistance of the material. In this case, a substantial amount of energy is dissipated within the plastic zone near the crack tip. Rubber toughening, however, is achieved at the expense of modulus. When the rigid particles are used, the toughening mechanism may consist of a combination of particle-matrix debonding, void formation around the particles and subsequent yielding of the interparticle matrix ligaments ${ }^{15}$.

A more recent method to improve the toughness off brittle polymers is interpenetrating network (IPN) grafting approach. Polyurethane is widely used material in interpenetrating network approach. Polyurethane (PU) resins are a unique family of materials that possess properties between plastics and of 
rubbers. There are several methods for the preparation of polyurethanes, but the most widely employed one is the reaction of di- or polyfunctional hydroxyl compounds, such as hydroxylterminated polyesters or polyethers with di- or polyfunctional isocyanate. A substantial amount of literature has been devoted to the toughening of epoxy resins through polyurethane incorporation as a second phase in a specific matrix to form an interpenetrating polymer network (IPN). It has been found that the mechanical properties of polymer materials with an interpenetrating network structure are fairly superior to those of ordinary polymers, specifically, the maximum tensile strength. Such improvement is generally believed to stem from an increase in crosslinking density within interpenetrating networks ${ }^{8}$.

The aim of the present work is an attempt to toughen epoxy polymer using a silane terminated urethane. With this aim, epoxy-based hybrid materials with various concentrations were prepared from bisphenol A-type epoxy resin and a silane terminated urethane. It is expected that in addition to a dispersed second phase formation, an interpenetrating network structure will also be formed through the addition of silane terminated urethane. The differences in the concentrations of the constituent parts of the hybrids should affect the mechanical properties of the resultant hybrids. The effects of silane terminated urethane content on the mechanical properties of hybrids were investigated. Tensile strength, three point bending, impact strength, hardness were conducted on the epoxy/silane terminated urethane specimens. The Fourier transform infrared (FT-IR) spectrum of the silane terminated urethane was recorded FT-IR spectrophotometer. The surfaces were observed by scanning electron microscope.

\section{EXPERIMENTAL}

Epoxy resin (epikote 828) and its hardener (epicure 205) were provided by Izomas Chemical, Turkey. As a catalyst for the crosslinking reactions of epoxy resin, a liquid tertiary amine accelerator, $\mathrm{N}, \mathrm{N}$-dimethylbenzoylamine (or known simply as benzyldimethylamine, BDMA), supplied by Aldrich was used to shorten the curing time.

Poly(hexamethylene carbonate) diol, 3-isocyanatopropyltrimethoxysilane (ICPTMS), tetraethoxysilane (TEOS), ethanol, $p$-toluenesulfonic acid (PTSA, catalyst), dibutyltin dilaurate (catalyst) and dimethyl acetamide (as a co-solvent) were purchased from Aldrich.

Characterization: The FTIR spectrum of silane terminated urethane was recorded on Shimadzu 8300 FTIR spectrophotometer. Mechanical properties of the epoxy/silane terminated urethane hybrid specimens were determined by standard tensile test to measure the modulus and tensile strength. Tensile and three point bending experiments were performed at room temperature on a materials testing system Zwick Z010, using a crosshead speed of $5 \mathrm{~mm} / \mathrm{min}$. Hardness was determined by Zwick Shore D. Izod impact test was conducted by using Zwick B5113.30 using 5.4 J Izod striker. The surfaces of the prepared specimens were observed by the JEOL JSM-5910 LV at an acceleration voltage of $20 \mathrm{kV}$. Five specimens were tested in each set and the average value was reported.

Prehydrolysis of tetraethoxysilane: Three grams of (14 mmol) tetraethoxysilane, $0.77 \mathrm{~g}$ (43 mmol) water and $p$-toluene- sulfonic acid (catalyst) in $1.33 \mathrm{~g}$ ethanol were mixed at $5^{\circ} \mathrm{C}$. The water/silicate ratio is calculated as $\mathrm{r}=3$. The mixture was allowed to warm to room temperature and stirred overnight.

Preparation of pre-hydrolyzed tetraethoxysilane containing silane terminated urethane (STU): Poly(hexamethylene carbonate) diol (5.01 g) and 3-isocyanatopropyltrimethoxysilane (ICPTMS) (0.515 g) were charged to a threenecked round bottom flask, fitted with a thermometer pocket, water condenser and a magnetic stirrer, filled with a $20 \%$ wt. dimethyl acetamide.

Dibutyltin dilaurate, at a concentration of $0.5 \%$, was added to the reaction flask as a catalyst. The temperature was raised to $60^{\circ} \mathrm{C}$ and the mixture was stirred for $24 \mathrm{~h}$. A schematic representation of this reaction is shown in Fig. 1. Completion of the reaction was confirmed by the disappearance of the characteristic -NCO peak at $2275 \mathrm{~cm}^{-1}$ in the FTIR spectrum (Fig. 2). The resultant mixture was stored in a refrigerator at $+4{ }^{\circ} \mathrm{C}$ until use. A $2.96 \mathrm{~g}$ of pre-hydrolyzed tetraethoxysilane added to above solution before mixing with catalysed epoxy.

Preparation of epoxy-silane terminated urethane solutions and specimens: Epikote 828 was used as the matrix material and Epicure 205 was used as liquid hardener. Epikote $828 /$ Epicure 205 ratio should be adjusted to $100 / 58$. The liquid hardener was slowly added to the epoxy resin at room temperature. This mixture was stirred until the two components miscibilized. Well mixed matrix material solutions appeared clear; therefore mixing was terminated when this condition was reached.

Then, previously prepared solutions of inorganic part (silane terminated urethane + pre-hydrolyzed tetraethoxysilane) were mixed with epoxy-hardener mixture to obtain hybrid solutions. The silane terminated urethane solution was added drop-by-drop into the stirred epoxy-hardener mixture in a glass tube (open system). Epoxy/silane terminated urethane mixtures were heated at $40^{\circ} \mathrm{C}$ in a vacuum oven for about 10 min to remove the trapped air formed during the mixing stage. Finally, $1 \%$ by weight of benzyl dimethyl amine was added as a catalyst. Various hybrid solutions were prepared using different epoxy/inorganic part solution compositions.

Fig. 3 showed the flow diagram of preparation of epoxy/ silane terminated urethane. There are 7 different compositions in which the inorganic component is varied at $0,5,10,15,20$, 25 and $30 \mathrm{wt}$. \%. These solutions were then cast into the tensile and impact specimen cavities of the molds made of Teflon and kept at room temperature for the curing purposes for $4 \mathrm{~h}$. Cured specimens were removed from the Teflon mold and test specimens prepared by cutting according to the dimensions specified in the relevant standards.

While creating own network structure of epoxy resin, added silane terminated urethane + pre-hydrolyzed tetraethoxysilane was formed their own network structure ${ }^{15}$. The expected structure is an interpenetrating network (Fig. 4).

\section{RESULTS AND DISCUSSION}

The tensile strength and E modulus values at room temperature for various types of epoxy/silane terminated urethane hybrids containing $0,5,10,15,20,25$ and $30 \mathrm{wt}$. \% equivalent were compared with those for the epoxy as given in Table-1. 
<smiles>O=CCCCCCCCCCCCCCCO</smiles>

Poly(hexamethylene carbonate) diol average $M_{n} \sim 2,000$<smiles>CCO[Si](C[N+](=O)[O-])(OCC)OCC</smiles>

3-Isocyanato propyl triethoxy silane (ICPTMS)

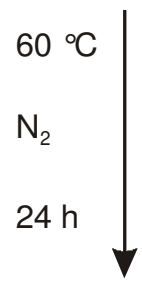

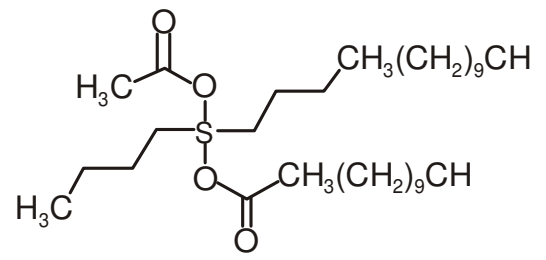

Dibutyltyne dilaurate

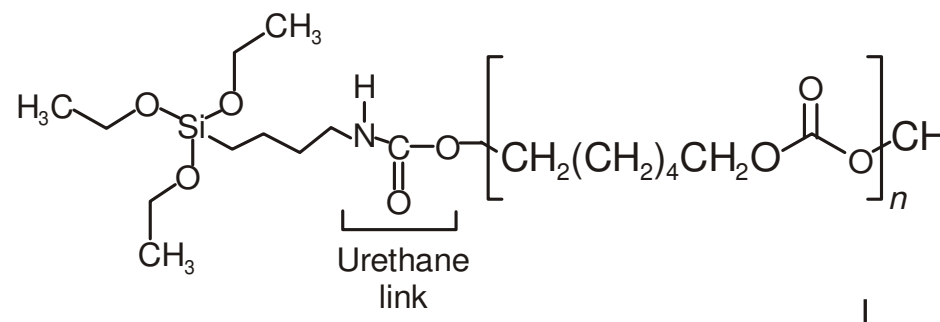

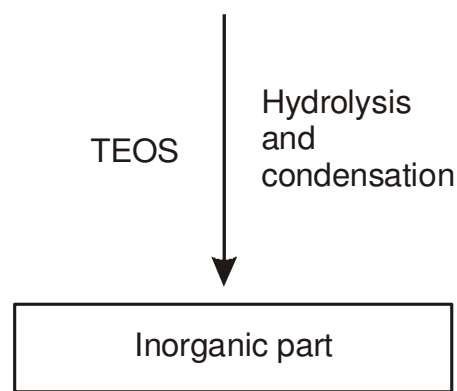

Fig. 1. Preparation of pre-hydrolyzed tetraethoxysilane containing silane terminated urethane

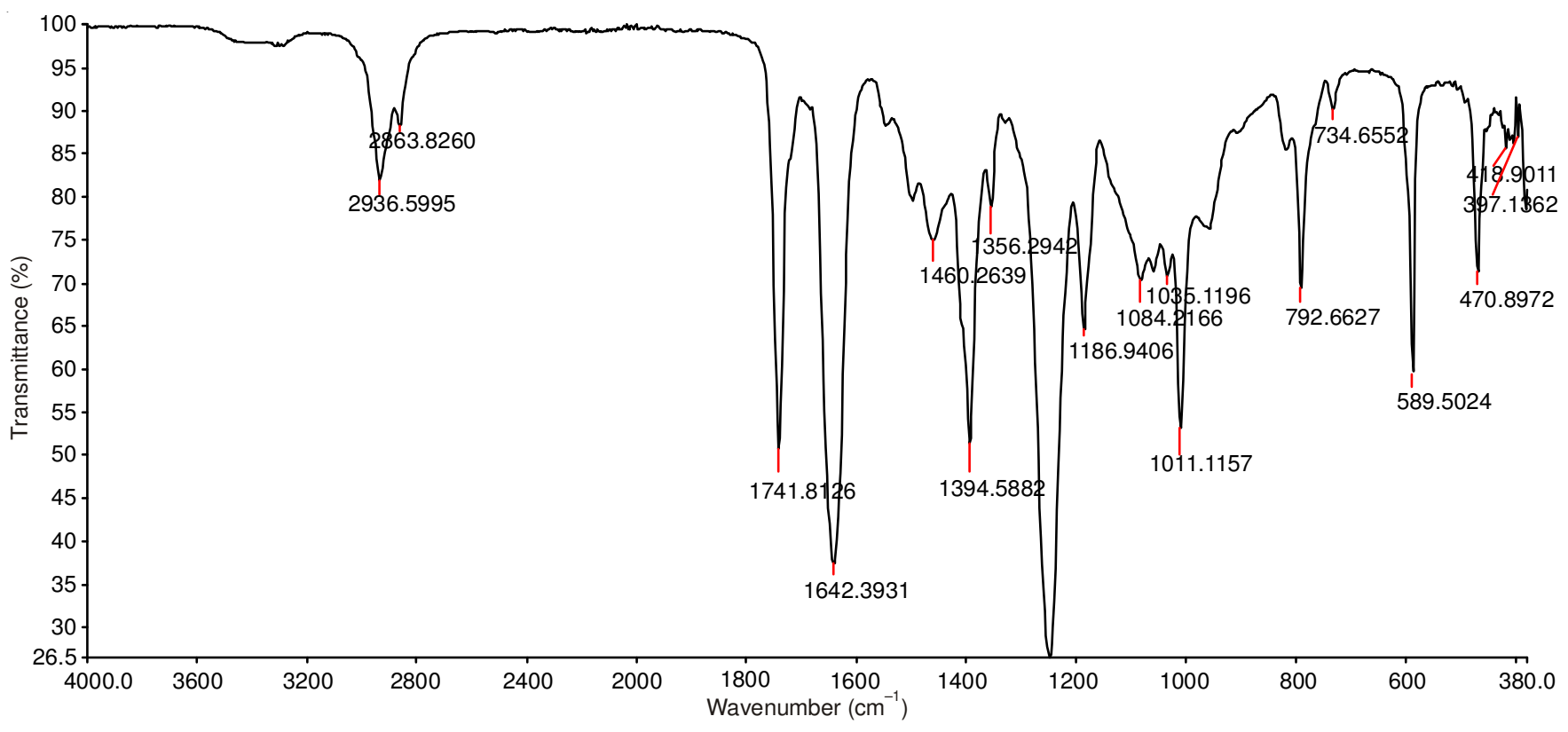

Fig. 2. FTIR spectrum of silane terminated urethane 


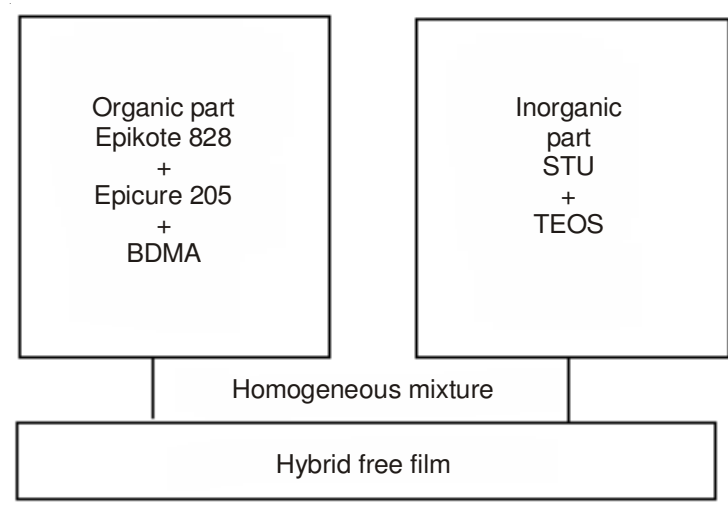

Fig. 3. Flow diagram of preparation of hybrid free film

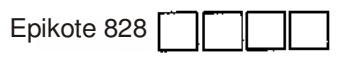

Epicure $205 \times$ x x X

BDMA

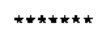

Crosslinking

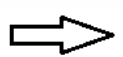

STU

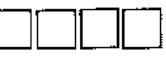

Pre-hydrolyzed $\times$ x $\times$ X

Fig. 4. A schematic representation expected IPN structure

TABLE-1

TENSILE PROPERTIES OF EPOXY + SILANE

TERMINATED URETHANE (STU) SPECIMENS

STU content (\%) (w) Tensile strength (MPa) $\quad$ E Modulus (MPa)

$\begin{array}{ccc}0 & 39 & 520 \\ 5 & 34 & 479 \\ 10 & 28 & 459 \\ 15 & 25 & 393 \\ 20 & 22 & 334 \\ 25 & 16 & 325 \\ 30 & 15 & 226\end{array}$

As expected, the differences in the concentrations of the constituent parts of the epoxy-based organic-inorganic hybrid materials should affect the mechanical properties of the resultant hybrids. As shown in Table-1, the addition of the silane component to epoxy reduced the tensile strength. Tensile strength was found to be highest for the pure epoxy specimens. Tensile strength decreased with increasing amount of silane terminated urethane in hybrid materials. The modulus of elasticity decreased also with increasing silane terminated urethane content as shown in Table-1.

As shown in Table-2, the addition of the silane component to epoxy increased the three-point bending strength for $5 \%$. Three-point bending strength was found to be highest for the $5 \%$ hybrid specimens. Then three-point bending strength decreased with increasing amount of silane terminated urethane in hybrid materials. The bending modulus of elasticity decreased with increasing silane terminated urethane content.

Izod impact strength values of the unnotched specimens were given in Fig. 5. With the addition of silane terminated urethane to epoxy resin the impact strength of resultant hybrid increased considerably. The increase in the impact strength
TABLE-2

THREE-POINT BENDING PROPERTIES OF EPOXY + SILANE TERMINATED URETHANE (STU) SPECIMENS

\begin{tabular}{ccc}
\hline $\begin{array}{c}\text { STU content }(\%) \\
(\mathrm{w})\end{array}$ & $\begin{array}{c}\text { Bending strength } \\
(\mathrm{MPa})\end{array}$ & $\begin{array}{c}\text { Bending } \\
\text { E Modulus (MPa) }\end{array}$ \\
\hline 0 & 39 & 495 \\
5 & 44 & 377 \\
10 & 43 & 362 \\
15 & 36 & 337 \\
20 & 23 & 234 \\
25 & 21 & 203 \\
30 & 16 & 196 \\
\hline
\end{tabular}

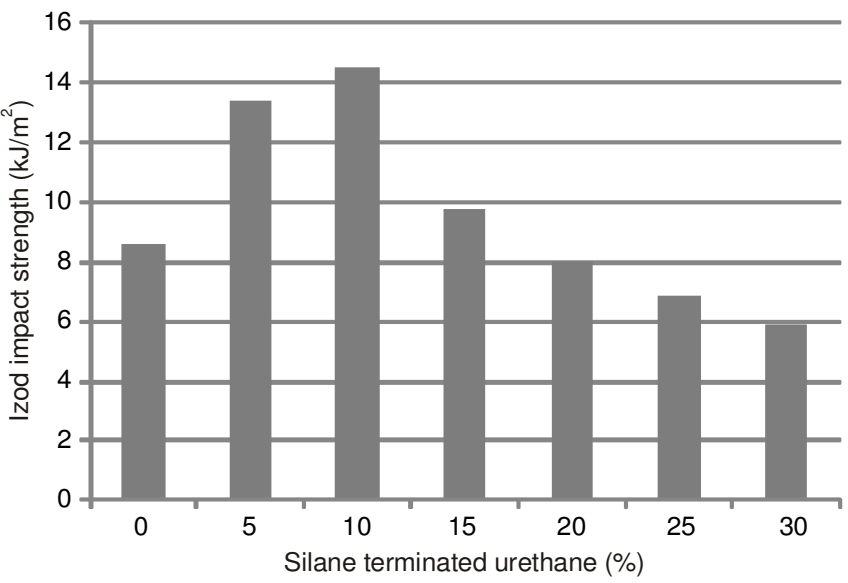

Fig. 5. Izod impact strength properties of epoxy + silane terminated urethane specimens

continued up to $10 \%$ silane terminated urethane addition. Impact strength of $10 \%$ silane terminated urethane added epoxy increased from 8.2 to $14.2 \mathrm{~kJ} / \mathrm{m}^{2}$. This was the highest impact value among the tested hybrids. Beyond this point, impact strength of hybrids started to decrease with increased amount of silane terminated urethane. Previous research regarding the toughening of epoxies through soft additions resulted similar limitations about the content of second phase. It is a well-known fact that in the toughening of epoxies through the addition of liquid rubbers such as CTBN and ATBN, there exist an optimum value of second phase ${ }^{16}$ which is about $18 \%$.

Hardness values were given in Fig. 6. The hardness of pure epoxy (control sample) was 63 Shore D whereas the addition of silane terminated urethane resulted in a hardness of 66 Shore $\mathrm{D}$ at the highest with $10 \%$ addition. However, after this point the hardness decreased gradually to below the control specimen for $15 \%$ silane terminated urethane addition.

The morphology of hybrid free films was examined by SEM. Fig. 7 shows the fracture surfaces of impact specimens having 5 and $20 \%$ silane terminated urethane. It can be seen (Fig. 7) that a second phase dispersed relatively uniformly over the fractured surfaces. Second phase particles are in micron and sub-micron scale. These particles are believed to cause the formation of crack pinning effect. A crack-pinning mechanism proposes that as a crack propagates through the resin, the crack front bows out between the second phase dispersion and remains pinned at the positions where it has encountered the particles. In other words, toughening may occur through the interaction between moving crack fronts and dispersed second phase particles. Particles act as barriers 


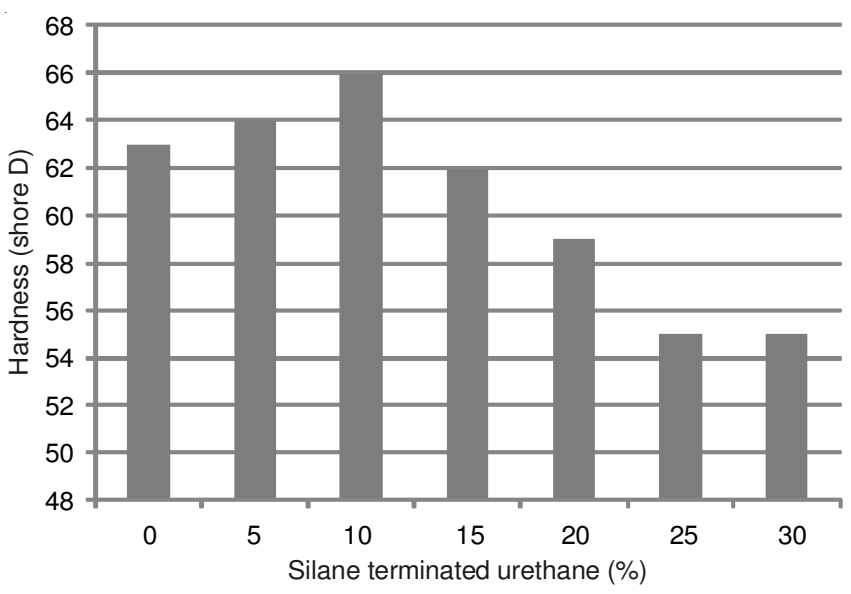

Fig. 6. Shore D hardness of epoxy + silane terminated urethane specimens
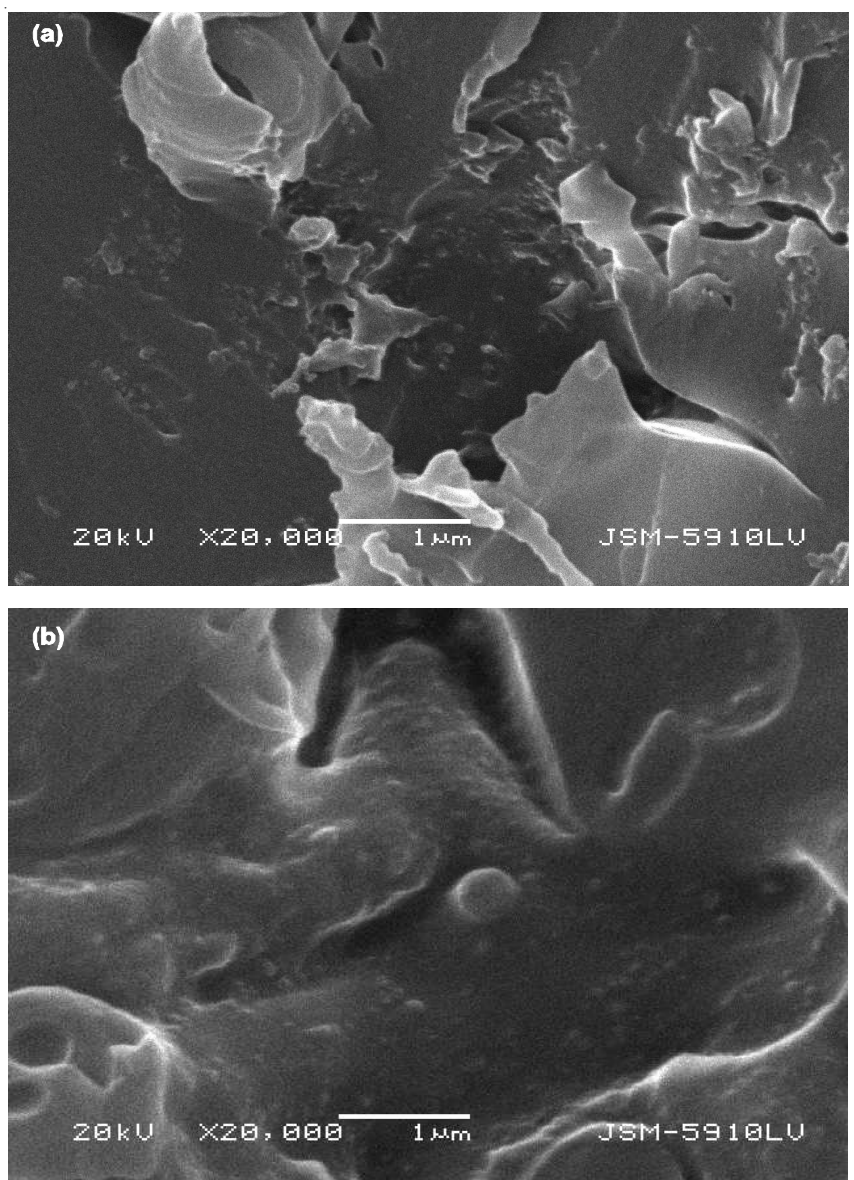

Fig. 7. SEM images of the epoxy + silane terminated urethane specimens: (a) $5 \%$ silane terminated urethane and (b) $20 \%$ silane terminated urethane

that pin a crack and so cause crack fronts to bow out between particles. During crack initiation, both a new fracture surface is formed and length of crack front increases ${ }^{17}$.

\section{Conclusion}

Addition of an elastomeric phase to epoxy matrix is one of the effective ways of overcoming the brittleness problem of epoxies. Soft modifiers may behave as excellent tougheners within brittle matrices. In this study a silane terminated poly- urethane oligomer was prepared as a soft modifier to toughen Epikote 828 epoxy resin. It was found that the incorporation of silane terminated polyurethane oligomer into epoxy resin was highly effective in toughening the epoxy resin. SEM pictures confirmed the presence of a micron and sub-micron scale dispersed second phase. However, it is believed that an interpenetrating network structure was also present within the structure in addition to presence of a dispersed second phase. They were both active in toughening. Tensile strength and E modulus values of hybrid free films reduced with the addition of silane terminated urethane. This reflects the rubber like behavior of silane terminated urethane. Bending modulus also exhibited a similar behavior to the tensile modulus. Addition of $10 \%$ silane terminated urethane was found to give the highest impact strength value which is $60 \%$ higher than the pure epoxy resin. Similarly, the hardness was also highest at $10 \%$ addition of silane terminated urethane.

From the above information, it can be concluded that silane terminated urethane is an effective toughening agent in the toughening of EPIKOTE 828 epoxy resin.

\section{ACKNOWLEDGEMENTS}

This work was supported by Marmara University, Commission of Scientific Research Projects under grant Project FENA-010710-0233.

\section{REFERENCES}

1. H. Yahyaie, M. Ebrahimi, H.V. Tahami and E.R. Mafi, Prog. Org. Coat., 76, 286 (2013).

2. M. Cakir, I. Kartal, H. Demirer and R. Samur, Sci. Res. Essays, 7, 805 (2012).

3. Y.F. Shih, R.J. Jeng and K.M. Wei, J. Anal. Appl. Pyrolysis, 70, 129 (2003).

4. H.J. Sue, P.M. Puckett, J.L. Bertram and L.L. Walker, in Eds.: R.A. Pearson, H.J. Sue and A.F. Yee, Toughening of Plastics, ACS Symposium Series 759, Washington, DC: American Chemical Society; p. 171 (2000).

5. A.S. Argon and R.E. Cohen, Polymer, 44, 6013 (2003).

6. J. Lee and A.F. Yee, Polymer, 42, 577 (2001).

7. K.P. Unnikrishnan, Ph.D. Thesis, Studies on the Toughening of Epoxy Resins, Department of Polymer Science and Rubber Technology, Cochin University of Science and Technology, Cochin, India (2006).

8. H. Harani, S. Fellahi and M. Bakar, J. Appl. Polym. Sci., 70, 2603 (1998).

9. A. Zudeldia, M. Larranga, P. Remiro and I. Mondragon, J. Appl. Polym. Sci. Part B, 42, 3920 (2004).

10. R. Bagheri and R.A. Pearson, Polymer, 41, 269 (2000).

11. R.J. Day, P.A. Lovell and A.A. Wazzan, Compos. Sci. Technol., 61, 41 (2001).

12. S. Kar and A.K. Banthia, J. Appl. Polym. Sci., 92, 3814 (2004).

13. J. Fröhlich, H. Kautz, R. Thomann, H. Frey and R. Mülhaupt, Polymer, 45, 2155 (2004).

14. S.P. Lin, J.L. Han, J.T. Yeh, F.C. Chang and K.H. Hsieh, Eur. Polym. J., 43, 996 (2007).

15. B. Wetzel, P. Rosso, F. Haupert and K. Friedrich, Eng. Fract. Mech., 73, 2375 (2006).

16. A.J. Kinloch, S.J. Shaw, D.A. Tod and D.L. Hunston, Polymer, 24, 1341 (1983).

17. A.J. Kinloch, R.J. Young, Fracture Behaviour of Polymers, Elsevier Applied Science Publishers, London (1983). 